\title{
Fruit Quality Characteristics That Affect Consumer Preferences for Satsuma Mandarins
}

\author{
Benjamin L. Campbell, ${ }^{1}$ Robert G. Nelson, ${ }^{1}$ Robert C. Ebel, ${ }^{2}$ \\ William A. Dozier, ${ }^{2}$ John L. Adrian, ${ }^{1}$ and Brandon R. Hockema ${ }^{2}$ \\ Alabama Agricultural Experiment Station, Auburn University, AL 36849
}

\section{Additional index words. conjoint analysis, market segmentation, Citrus unshiu}

\begin{abstract}
Satsuma mandarins (Citrus unshiu) have been produced intermittently along the Gulf Coast for over a century. However, very little is known about the market potential for this citrus fruit in today's consumer markets. This study evaluated consumer preferences for seven external attributes over a range of levels: price $(\$ 1.07, \$ 2.18$, or $\$ 4.39 / \mathbf{k g})$, color (green-yellow, yellow-orange, or orange), size $(5.08,6.35$, or $7.62 \mathrm{~cm}$ in diameter), seediness $(0,3$, or 7 seeds), blemishes $(0,1.91$, or $3 \mathrm{~cm}$ in diameter), production region label (Alabama or U.S.A.), and organic production (yes or no). Consumers from grocery stores in nine cities in Alabama and Georgia were asked to evaluate 20 photographs of various combinations of these attribute levels using a seven-point intention-to-buy scale. 605 useable surveys were collected and a conjoint analysis was conducted to determine the strength of preference for the attribute levels and the relative importance for attributes. Three consumer segments were identified by cluster analysis of strengths of preferences: the no-blemish segment ( $37 \%$ of sample), the price-sensitive segment ( $23 \%$ of sample), and the no-seeds segment ( $41 \%$ of sample). A multinomial logit analysis identified several demographic, socioeconomic, and usage variables as significant determinants of segment membership.
\end{abstract}

Satsuma mandarins (Citrus unshiu) have long been a delicacy throughout the world. Satsumas are similar to tangerines, but are generally easier to peel, seedless and less acidic tasting. During the early $20^{\text {th }}$ century, the Gulf Coast region was a substantial producer and exporter of satsumas, and was even nicknamed Satsumaland (Rucker, 1996). Alabama alone had 4,856 bearing hectares, with fruit exports peaking at over one million dollars in 1923 (Dozier, 1924), a value of $\$ 10.78$ million in today's dollars. Following 3 decades of growth and success after the turn of the century, the industry was decimated in the 1930 s by several major freezes (Winberg, 1948).

During the early 1990s, the satsuma industry began reemerging along the Gulf Coast due to renewed interest in satsuma production by several coastal growers. The region provides excellent growing conditions that produce a high-quality product (Ebel et al., 2004). These conditions make the industry worthy of consideration for a revitalization effort.

Received for publication 5 Nov. 2003. Accepted for publication $20 \mathrm{Jan}$. 2004. This project was funded in part by the Alabama Department of Agriculture and Industries, a grant from the USDA Federal-State Marketing Improvement Program, and the Alabama Agricultural Experiment Station. We thank Terry Rodriguez for helping with photo design and development, Deacue Fields and Floyd Woods for reviewing the manuscript, and Bruno's Supermarkets, Inc., The Kroger Company, and Piggly Wiggly Company for their cooperation in conducting the survey.

${ }^{1}$ Department of Agricultural Economics and Rural Sociology, 202 Comer Hall, Auburn University, AL 36849. Corresponding author; e-mail rnelson@acesag.auburn.edu.

${ }^{2}$ Department of Horticulture, 101 Funchess Hall, Auburn University, AL 36849.
Due to increased production, market expansion is becoming a pressing issue for continued growth of the industry. However, what is currently known about consumer preferences for satsumas is at best an educated guess because the satsuma is a relatively unknown product in the U.S. To gain a better understanding of consumer preferences for satsumas, the overall objective of the research was to identify and assess consumer preferences for key satsuma attributes. For this initial study, the key attributes identified were the external, visual, non-taste characteristics that play a major role in the consumer's initial buying decision, such as price, skin color, fruit size, etc. Determining consumer preferences for these attributes will allow satsuma growers to understand what qualities of fruit are most appealing to consumers. Satsumas can then be grown to those specifications, thereby improving consumer satisfaction, domestic market expansion, and grower revenues.

\section{Materials and Methods}

Conjoint analysis was the technique chosen to analyze consumer preferences for external satsuma characteristics. Conjoint analysis relies on the premise that a consumer's valuation of a product is based on the utility or satisfaction derived from the many attributes that comprise the product as a whole (Baker, 1998). Therefore, a consumer's overall valuation of a satsuma would depend on the consumer's combined preference for all the different attributes and specific levels exhibited by the product. By allowing consumers to evaluate enough combinations of attribute levels, an estimate for each level's contribution to the overall valuation can be obtained. Conjoint analysis can be used to identify the optimal product form, measure the relative importance of attributes in the buying decision, characterize consumer segments within the market, and simulate the effects of pricing strategies (Hair et al., 1998).

The conjoint technique is "by far, the most used marketing research tool for analyzing consumer tradeoffs" (Green et al., 2001). Conjoint analysis has been used to determine consumer preferences for fruit and vegetables (Baker, 1998, 1999; Baker and Crosbie, 1994; Frank et al., 2001; Lin et al., 1996; Manalo, 1990; van der Pol and Ryan, 1996), food attribute preferences (Baker and Burnham, 2002; Fotopoulos and Krystallis, 2001; Gillespie et al., 1998; Halbrendt et al., 1991; Harrison et al., 1998; Holland and Wessells, 1998; Martínez et al., 2002), and other horticultural products (Behe et al., 1999; Gineo, 1990; Kelley et al., 2001, 2002; Robertson and Chatfield, 1982; Shafer and Kelly, 1986; Townsley-Brascamp and Marr, 1995).

The first step of any conjoint study is the identification of key attributes and their appropriate levels. After consulting with horticulture experts, food distributors, and satsuma producers, seven attributes were identified as important to consumers, including: price, skin color, fruit size, area of surface blemishes, seediness, production region label, and organic production practices. Other external attributes were excluded because they were deemed to be of limited importance in the buying decision. Internal attributes such as taste and smell are being considered in another study using a different methodology.

Product price is usually important to most consumers. In previous conjoint studies of food products, consumer segments were shown to have widely-varying relative importance for price in the buying decision, ranging from $5 \%$ in an apple study (Baker and Crosbie, 1994) to $78 \%$ in a peanut butter study (Nelson et al., 2004). In this study, price was assigned three levels - $\$ 1.07, \$ 2.18$, and $\$ 4.39 / \mathrm{kg}$, which represented the lowest, most common, and highest mandarin prices found in stores sampled in Alabama and Georgia in 2001 and 2002.

Skin color is another attribute that is typically important to consumers when they purchase fruit. According to previous conjoint studies, color has shown a relative importance between $20 \%$ for apples (Manalo, 1990) and 93\% for bell peppers (Frank et al., 2001). Three color levels were chosen for evaluation: green-yellow, yellow-orange, and orange. These color levels reflect the changes in skin color that a fruit experiences during maturation. Satsumas are among the few citrus fruits that can be ripe and edible when they are still green (Walheim, 1996). By allowing consumers to evaluate a green-yellow fruit, researchers can determine what percentage of consumers equate greenish color with fruit immaturity. If a segment of consumers already understands that green-yellow satsumas can be ripe, then retailers may be more willing to buy these colors, thereby enabling growers to move fruit into the market earlier, or without having to incur the cost of fruit coloration. 
Manalo (1990) found that size had a relative importance of $20 \%$ for apples. According to a prominent fruit-marketing manager (Marderoshi, personal communication), most grocery stores want sweet citrus in the size range of large medium (5.41 to $5.72 \mathrm{~cm})$ to jumbo $(6.35$ to $6.99 \mathrm{~cm}$ ), using the terminology of California satsuma growers. Three levels of size were used in this study: $5.08,6.35$, and $7.62 \mathrm{~cm}$.

Number of seeds per fruit was also considered important. Three seed levels were represented in this study: 0,3 , and 7 seeds. Satsumas normally have few or no seed and are considered to be commercially seedless (Walheim, 1996), which is defined as having no more than six seeds per fruit (Powell and Williams, 1998).

The attribute of being organic was thought to be important to obtain an understanding of the value of this production method to consumers. Tobe labeled organic, growers must meet USDA and state requirements. This attribute had only two levels, which were described in this study simply as "organically grown? = yes/no."

The production region label also consisted of only two levels: produced in = Alabama/U.S. These levels allowed the researchers to determine if an Alabama label had any advantage in name or brand recognition for consumers, compared to the U.S. control.

Blemishes are a problem for satsuma growers because they are a relatively common occurrence due to a variety of biotic and abiotic factors. Fruit may be damaged by wind, birds, diseases and insects. At this time, there are no standards specifically designated for grading satsumas based on amount of blemish, so the USDA standards for mechanical blemishes (scarring) of Florida tangerines were used (USDA-AMS, 2002). Based on these standards, three blemish levels were chosen. The first level consisted of no surface blemish, which meets the USDA requirement for Fancy grade tangerines. The second level represented a blemish with a diameter of $19.1 \mathrm{~mm}$. This size blemish is classified as damaged, which falls in the USDA \#1 grade. A blemish with a diameter of $28.6 \mathrm{~mm}$ was used as the third level, which represents a seriously damaged fruit and is classified as a USDA \#3 grade. Any amount of blemish greater than $28.6 \mathrm{~mm}$ is considered a cull. The method of using photographs to reflect varying amounts of surface defect has been used in several other studies (Baker, 1998, 1999).

To examine all seven attributes and their levels would have involved 972 combinations $\left(3^{5} \times 2^{2}\right)$, which is an impractical number of product profiles to evaluate. However, by using a fractional-factorial design generated by Conjoint Designer (Bretton-Clark, Morristown, N.J.) it was possible to reduce the number of required profile stimuli to 20 , while maintaining orthogonality within stimulus design (Hair et al., 1998).

Twenty photographs containing the selected attribute combinations were used as stimuli. Numerous other studies have used pictorial representations (Baidu-Forson et al., 1997; Baker, 1998, 1999; Baker and Crosbie, 1994; Behe et al., 1999). For purposes of this study, pictorial stimuli made the evaluation exercise more interesting than simple text descriptions, while transmitting external attribute information more realistically (Green et al., 2001).

Pictures of fruit with the appropriate attribute levels were developed in several stages. First, fruit samples were harvested on each of three occasions starting in October 2002 and ending in late November 2002. The fruit samples were numbered and recorded as displaying a certain color, such as green-yellow, yellow-orange, or orange, based on subjective visual examination. Since skin color was not uniform over the entire fruit, the part displaying the desired color, usually a half or quarter of the fruit, was framed using strips of tape. Next, color readings from within the framed area were taken using a spectrometer (model CM-2002; Minolta Camera Co., Japan). Color readings included standard $\mathrm{L}^{*}, \mathrm{a}^{*}$, and $\mathrm{b}^{*}$ measurements. $\mathrm{L}^{*}$ indicates the luminance or lightness of the fruit, with a reading of 0 representing black, and 100 representing white. The $\mathrm{a}^{*}$ value defines a color on a purple-redblue-green axis, while $\mathrm{b}^{*}$ indicates a color's coordinates on a yellow-blue axis (McGuire, 1992; Voss, 1992). Readings from the framed section were taken in five predetermined locations: the four corners and the middle of the frame. Fruit were then photographed with a digital camera to reproduce their color in a digital format.

Since it was difficult to know when a fruit would reach the orange color stage, we exposed the earliest samples to an ethylene atmosphere to accelerate the development of skin color to the final stage. Once a fruit changed from green-yellow to yellow-orange based on visual examination of the fruit, color readings and a photograph were again taken in the same location as before. Fruit were then reintroduced into an ethylene atmosphere in order to obtain the orange color, and color readings and a photograph were again taken as before. As it turned out, fruit harvested later in the season progressed naturally to the orange stage, allowing for photographs and color readings of both ethylened and naturally colored fruit to be obtained.

During the photography phase, an archetypal fruit was identified, having the classic oblate shape and no blemishes or unusual marks. This archetypal fruit was used as the model in all 20 photographs, in order to eliminate variations in shape and skin texture that would be expected if different fruit were used for each photograph.

Table 1. Skin color readings used in developing the "color" attribute (five readings per fruit).

\begin{tabular}{|c|c|c|c|c|c|c|}
\hline Color & Measure & $\begin{array}{l}\text { No. of } \\
\text { fruit } \\
\text { sampled }\end{array}$ & $\mathrm{n}$ & $\begin{array}{l}\text { Mean } \\
\text { value }\end{array}$ & $\begin{array}{l}\text { Standard } \\
\text { deviation }\end{array}$ & $\begin{array}{c}\text { Coefficient } \\
\text { of variation } \\
(\%)\end{array}$ \\
\hline Green-yellow & $\mathrm{L}^{*}$ & 25 & 125 & 60.20 & 5.31 & 9 \\
\hline Green-yellow & $a^{*}$ & 25 & 125 & 1.79 & 7.86 & 439 \\
\hline Green-yellow & $b^{*}$ & 25 & 125 & 54.49 & 7.59 & 14 \\
\hline Yellow-orange & $\mathrm{L}^{*}$ & 25 & 125 & 64.88 & 3.78 & 6 \\
\hline Yellow-orange & $a^{*}$ & 25 & 125 & 20.50 & 4.66 & 23 \\
\hline Yellow-orange & $b^{*}$ & 25 & 125 & 64.60 & 5.43 & 8 \\
\hline Orange & $\mathrm{L}^{*}$ & 26 & 130 & 63.28 & 2.74 & 4 \\
\hline Orange & $a^{*}$ & 26 & 130 & 28.44 & 2.40 & 8 \\
\hline Orange & $b^{*}$ & 26 & 130 & 62.99 & 3.88 & 6 \\
\hline
\end{tabular}

Average $\mathrm{L}^{*}, \mathrm{a}^{*}$, and $\mathrm{b}^{*}$ color readings were calculated for the five sampling locations in the frames on the 25 to 26 fruit in each of the green-yellow, yellow-orange, and orange categories (Table 1). The average values were then inputted into Adobe's Photoshop 7 (Adobe Systems Inc., Seattle, Wash.) to change the color of the model fruit to the desired color. This process allowed for the creation of three fruit that were identical except for color.

Next, pictures of fruit halves with the required number of seeds were produced. Fruit were first cut in half to determine seed content, and since fruit with 0 and 3 seeds were among the natural harvest, photographs were taken of those halves directly. However, to create the 7 -seed picture, four additional seeds were physically pressed into the three-seed fruit, and then photographs were taken.

To achieve the final sizes needed, the dimensions of the whole and half fruit had to be digitally adjusted. Images of the model fruit were reduced or enlarged so that the printed version displayed the actual diameters specified in the experimental design.

A representative blemish, typical of windscarring, was also photographed during the initial sampling process. After the model fruit was colored and sized, the blemish was digitally applied to those photographs needing a 19.1 or 28.6-mm-diameter blemish.

Final photographs were developed in Adobe Photoshop 7 (Adobe Systems Inc.) to a standard $21.6 \times 27.9-\mathrm{cm}$ print. The pictorial stimuli included the following views in four quadrants: top, bottom, side, and half, with a large letter (A through T) in the middle, which corresponded with the panel letter in the questionnaire. An entire display board, measuring $21.6 \times 33.7 \mathrm{~cm}$, consisted of the four pictorial stimuli depicting color, size, blemishes, and seeds, plus text above indicating price, and text below indicating production region label, and type of production.

Surveys were administered in nine cities in Alabama and Georgia on different days of the week. Surveying for some stores lasted 2 $\mathrm{d}$ while for others only $1 \mathrm{~d}$; however, the total amount of time spent in each store was around 8 h. Cities surveyed in Alabama included Auburn, Birmingham, Gadsden, Huntsville, Mobile, and Montgomery. Cities surveyed in Georgia were Albany, Columbus, and Macon. Surveys were conducted in five different supermarket chains, including Bruno's (4), Food Max (1), Food World (2), Kroger (1), and Piggly Wiggly (1).

Within the stores, display boards were set 
up on tables (usually in or near the produce department) so that the photographs would be at chest level of most respondents. Consumers passing by the table were asked to participate in the survey. The survey consisted of the 20 pictorial stimuli and 14 demographic questions. To reduce order bias, the stimuli were reordered after the third and sixth stores. In addition, respondents could start the survey at any point around the table.

Respondents were asked to evaluate the 20 stimuli on a 7 -point rating scale, with $1=$ definitely would NOT buy, $7=$ definitely would buy, 4 = may or may not buy, and 2, 3, 5, and $6=$ intermediate responses. Respondents could also place their mark anywhere between the integers, and these were later measured with a ruler and recorded to the nearest tenth of a rating point.

After completing the conjoint section of the survey, respondents answered 14 questions on usage, demographic, and socio-economic characteristics. The 8 usage questions included previous consumption of sweet citrus (yes/no), allergic reaction to sweet citrus (yes/no), sweet citrus purchase frequency (number of times per month), pounds of sweet citrus purchased each time, location of purchase (grocery store, farmers market, roadside stand, or other), special occasion purchasing (Christmas, special events, etc.), awareness of satsumas (yes/no), and previous consumption of satsumas (yes/ no). The six demographic and socio-economic questions consisted of year of birth, gender, ethnic group, years of education, age structure of family (number of persons in each age group), and income category.

A total of 605 usable surveys were collected. Ordinary least squares regression was used to estimate each respondent's preference coefficients for attribute levels. The following specification was used:

$\mathrm{R}_{\mathrm{i}}=\mathrm{B}_{1}+\mathrm{B}_{2}(\mathrm{P} 2)+\mathrm{B}_{3}(\mathrm{P} 3)+\mathrm{B}_{4}(\mathrm{C} 2)+\mathrm{B}_{5}(\mathrm{C} 3)+$ $\mathrm{B}_{6}(\mathrm{~S} 2)+\mathrm{B}_{7}(\mathrm{~S} 3)+\mathrm{B}_{8}(\mathrm{BM} 2)+\mathrm{B}_{9}(\mathrm{BM} 3)+\mathrm{B}_{10}(\mathrm{SD} 2)$ $+\mathrm{B}_{11}(\mathrm{SD} 3)+\mathrm{B}_{12}(\mathrm{BR} 2)+\mathrm{B}_{13}(\mathrm{O} 2)+\mathrm{E}_{\mathrm{j}}$

where, $R_{j}$ denotes rating value given by respondent $\mathrm{j}$ on the 7-point scale; $\mathrm{P} 2=\$ 2.18 / \mathrm{kg}$ price level; $\mathrm{P} 3=\$ 4.39 / \mathrm{kg}$ price level; $\mathrm{C} 2=$ yellow-orange skin color; $\mathrm{C} 3=$ orange skin color; $\mathrm{S} 2=6.35 \mathrm{~cm}$ diameter fruit; $\mathrm{S} 3=7.62$ $\mathrm{cm}$ diameter fruit; $\mathrm{BM} 2=19.1 \mathrm{~mm}$ diameter blemish; BM3 = $28.6 \mathrm{~mm}$ diameter blemish; $\mathrm{SD} 2=3$ seeds $; \mathrm{SD} 3=7$ seeds $; \mathrm{BR} 2=$ U.S.A. production region label; and $\mathrm{O} 2=$ type of production is not organic.

The reference profile is a fruit displaying the following characteristics: $\$ 1.07 / \mathrm{kg}$, greenyellow, $5.08 \mathrm{~cm}$ size, 0 amount of blemish, 0 seed, grown in Alabama, and organic. The independent variables were effects coded, that is, instead of coding data with the customary 0 or one values, effects coding uses a 0 , one, and negative one coding scheme. This coding scheme serves two purposes. First, coefficients for the reference category can be simply calculated by subtracting the other levels within an attribute from 0 . That is, the value needed for the sum of all the attribute levels to equal 0 is the coefficient for the reference category.
Second, the coefficients are transformed from deviations from the reference category into deviations from the intercept or overall mean (Hair et al., 1998), which makes interpretation easier when the coefficient estimates are added or subtracted from the intercept in order to determine expected ratings from any combination of attribute levels.

The coefficient estimates are used to provide information regarding the relative importance of an attribute in the consumer's buying decision. The relative importance is calculated by the following formula:

$$
\mathrm{RI}_{\mathrm{i}}=\left(\text { (ange }_{\mathrm{i}} \times 100\right) / \sum\left(\text { (ange }_{\mathrm{i}}\right) ; \mathrm{i}=1-7
$$

where $\mathrm{RI}_{\mathrm{i}}$ is the relative importance of attribute $i$ and range is the range of the consumer's coefficients for attribute $i$. The resulting values are interpreted as fractional components of a consumer's buying intention.

Identifying consumer segments within a market is an important part of the marketing process for agribusiness enterprises. Cluster analysis provides a method of identifying these market segments by using the regression estimates obtained from the conjoint analysis and grouping respondents with similar coefficients into clusters (Green and Helsen, 1989).

The process of determining an appropriate number of clusters is somewhat subjective, so several clustering techniques were used, including Ward, McQuitty, Equal Variance Maximum Likelihood, Flexible Beta, and Complete Linkage (SAS, 1987). Results indicated that there could be between two and ten clusters, with three and five clusters being the most frequently indicated.

A flexible approach described in the SAS/ STAT User's Guide (1987) was used to refine the clusters. The FASTCLUS procedure was first used to form up to 30 clusters after eliminating outliers, which were defined as clusters with small membership (i.e., $<6$ observations). FASTCLUS starts by forming cluster seeds, or temporary cluster means. Then observations are assigned to the nearest cluster seed, at which point the cluster seed is updated. Finally, all observations are assigned to a cluster and the cluster seed is replaced by the actual cluster mean. Since the previous clustering methods indicated the possible presence of up to 10 clusters, the CANDISC procedure was used to produce plots of all cluster sizes up to 10 clusters, using the first and second canonical discriminant variables as the axes. Visual examination of the plotted clusters indicated that the 3-cluster produced the most differentiated groups, so each respondent was assigned to one of these 3 clusters.

After the three consumer segments (clusters) were identified, LIMDEP (Greene, 1995) was used to run a multinomial logit model in order to evaluate the probability of membership in a specific segment based on the demographic, socio-economic, and usage variables of segment members. From the multinomial logit model, the marginal effects can be obtained, which allow for changes in probabilities of segment membership to be examined. For instance, if a consumer is male, then we might find that his probability of membership in Segment I would decrease by $6.5 \%$. The multinomial logit procedure is described further in Frank et al. (2001) and Huang and $\mathrm{Fu}$ (1995). The results, to be discussed below, can be extrapolated to the population as a whole only if the sample is representative of the population. Therefore, any extrapolation from the sample to the overall population should keep this limitation in mind.

\section{Results and Discussion}

Overall sample. As a whole, the sample of 605 respondents placed the highest relative importance on seeds $(22.7 \%)$, followed by price (16.6\%), blemish (16.6\%), color (15.7\%), size $(13.9 \%)$, type of production $(7.5 \%)$, and production region label $(6.9 \%)$ (Table 2$)$. However, the overall sample results do not allow for segmentation of consumers based on the variability of preferences among consumers. The following segmentation analysis reveals this variability.

Market segments. The three segments identified by cluster analysis were subjectively described as the no-blemish, price-sensitive, and no-seed segments, based on their attributes of highest relative importance. Segment I, the no-blemish segment, represented $37 \%$ of the total respondents. Their highest relative importance score $(25 \%)$ was for the blemish attribute, although the skin color attribute was a close second at $20 \%$. For this segment, a fruit displaying 0 blemish received an average rating increase of 0.91 on the 7-point intention-to-buy scale, or a $23 \%$ increase over the average base rating (Table 2). Conversely, a fruit displaying a $28.6 \mathrm{~mm}$ blemish elicited an average coefficient of -0.58 , representing a $15 \%$ decrease in base rating. Green-yellow fruit received a $14 \%$ decrease from the average base rating, while yellow-orange and orange received $9 \%$ and $5 \%$ increases, respectively.

The no-blemish segment was of a significantly younger age (39 vs. 43 overall), had the lowest percentage of whites $(56 \%$ vs. $70 \%$ overall), was in a slightly lower income category (4.84 vs. 5.24 overall), had the highest percentages of households with at least one child under the age of nine (34\% vs. $27 \%$ overall) and young adults (52\% vs. $43 \%$ overall) (Table 2).

The distribution of preferred levels for Segment I (Table 3) was more complex than indicated by the average preference coefficients in Table 2. Even though $84 \%$ of Segment I would choose no blemishes as their first choice or preferred level, another $16 \%$ would choose some amount of blemishes, despite the fact that the average coefficients for these levels were negative. Similarly, while $86 \%$ preferred the yellow-orange or orange colors, as many as $14 \%$ preferred the green-yellow color, indicating that there may be some non-negligible demand for fruit that is still slightly green.

Examination of the marginal probabilities indicated that several demographic variables might be influential (Table 4). As with any coefficient, the sign, magnitude and $p$ value or significance level are all of interest. However, 
in the case of conjoint studies, the marginal probabilities from demographics are often disappointingly unrevealing, either because they do not pass a conventional test of significance (say, $p<0.10$ ) or because the coefficient itself, though statistically significant, is very small in magnitude and influence. In this type of exploratory study, we believe that increasing the chance of committing a Type I error does not incur substantial costs, so we may discuss

Table 2. Preference coefficients, relative importance, adjusted $R^{2}$ and demographics for segments and overall sample.

\begin{tabular}{|c|c|c|c|c|}
\hline $\begin{array}{l}\text { Attributes } \\
\text { and levels }\end{array}$ & $\begin{array}{c}\text { Segment } \\
\text { I }\end{array}$ & $\begin{array}{c}\text { Segment } \\
\text { II }\end{array}$ & $\begin{array}{c}\text { Segment } \\
\text { III }\end{array}$ & $\begin{array}{l}\text { Overall } \\
\text { sample }\end{array}$ \\
\hline $\mathrm{N}$ & 223 & 137 & 245 & 605 \\
\hline Market share (\%) & 36.9 & 22.6 & 40.5 & 100.0 \\
\hline Intercept (base rating) & 4.02 & 3.85 & 3.98 & 3.97 \\
\hline \multicolumn{5}{|l|}{ Price/kg } \\
\hline$\$ 1.07$ & $0.00^{*}$ & $0.97^{*}$ & $-0.03^{*}$ & 0.21 \\
\hline$\$ 2.18$ & $0.07^{*}$ & $0.29^{*}$ & 0.20 & 0.17 \\
\hline$\$ 4.39$ & $-0.07^{*}$ & $-1.26^{*}$ & $-0.17^{*}$ & -0.38 \\
\hline Relative importance $(\%)$ & 12.5 & 30.8 & 12.5 & 16.6 \\
\hline \multicolumn{5}{|l|}{ Size (cm diameter) } \\
\hline 5.08 & -0.37 & -0.30 & -0.32 & -0.34 \\
\hline 6.35 & 0.13 & 0.05 & 0.08 & 0.09 \\
\hline 7.62 & 0.25 & 0.26 & 0.24 & 0.25 \\
\hline Relative importance $(\%)$ & 13.2 & 13.1 & 13.6 & 13.9 \\
\hline \multicolumn{5}{|l|}{ Color } \\
\hline Green-yellow & $-0.56^{*}$ & $-0.23^{*}$ & -0.30 & -0.38 \\
\hline Yellow-orange & $0.36^{*}$ & $0.09^{*}$ & 0.19 & 0.23 \\
\hline Orange & 0.20 & 0.14 & 0.11 & 0.15 \\
\hline Relative importance (\%) & 19.8 & 13.1 & 13.4 & 15.7 \\
\hline \multicolumn{5}{|l|}{ Number of seeds } \\
\hline 0 & $0.12^{*}$ & $0.34^{*}$ & $1.27^{*}$ & 0.63 \\
\hline 3 & -0.01 & 0.02 & -0.05 & -0.02 \\
\hline 7 & $-0.11^{*}$ & $-0.35^{*}$ & $-1.22^{*}$ & -0.62 \\
\hline Relative importance $(\%)$ & 13.2 & 15.5 & 35.4 & 22.7 \\
\hline \multicolumn{5}{|l|}{ Diameter of surface blemish (mm) } \\
\hline 0 & $0.91^{*}$ & $0.12^{*}$ & $0.19^{*}$ & 0.44 \\
\hline 19.1 & $-0.33^{*}$ & $-0.02^{*}$ & $-0.02^{*}$ & -0.14 \\
\hline 28.6 & $-0.58^{*}$ & $-0.10^{*}$ & $-0.16^{*}$ & -0.30 \\
\hline Relative importance $(\%)$ & 24.9 & 11.3 & 12.0 & 16.6 \\
\hline \multicolumn{5}{|l|}{ Production region label } \\
\hline Alabama & $-0.06^{*}$ & 0.09 & $0.11^{*}$ & 0.04 \\
\hline U.S. & $0.06^{*}$ & -0.09 & $-0.11^{*}$ & -0.04 \\
\hline Relative importance $(\%)$ & 6.7 & 7.7 & 6.6 & 6.9 \\
\hline \multicolumn{5}{|l|}{ Type of production } \\
\hline Organic & 0.07 & 0.08 & 0.05 & 0.06 \\
\hline Conventional & -0.07 & -0.08 & -0.05 & -0.06 \\
\hline Relative importance (\%) & 7.9 & 8.5 & 6.6 & 7.5 \\
\hline Adjusted $R^{2}$ & 0.49 & 0.51 & 0.55 & 0.52 \\
\hline \multicolumn{5}{|l|}{ Survey city (\% of segment) } \\
\hline Auburn, Ala. & 8 & 15 & 12 & 11 \\
\hline Columbus, Ga. & $19^{*}$ & 11 & 11 & 14 \\
\hline Montgomery, Ala. & 11 & 9 & 16 & 12 \\
\hline Birmingham, Ala. & 11 & 14 & 15 & 13 \\
\hline Gadsden, Ala. & 9 & $20^{*}$ & 12 & 13 \\
\hline Huntsville, Ala. & 13 & 7 & 10 & 11 \\
\hline Albany, Ga. & 12 & 12 & 15 & 13 \\
\hline Macon, Ga. & $11^{*}$ & 4 & 4 & 6 \\
\hline Mobile, Ala. & 5 & 7 & 6 & 6 \\
\hline Ever eaten sweet citrus ( $\%$ yes) & 97 & 99 & 98 & 98 \\
\hline Allergic to sweet citrus (\% yes) & 8 & 11 & 6 & 8 \\
\hline Sweet citrus purchases $\left(\mathrm{kg} \cdot \mathrm{month}^{-1}\right)$ & 5.95 & 4.90 & 5.07 & 5.31 \\
\hline Buy citrus at grocery store (\% yes) & 86 & $81^{*}$ & 90 & 87 \\
\hline Special occasion purchase? (\% yes) & 38 & 39 & 47 & 42 \\
\hline Age (years) & $39.14^{*}$ & $45.93^{*}$ & 44.26 & 42.75 \\
\hline Gender ( $\%$ female) & 67 & 61 & 60 & 63 \\
\hline Ethnicity (\% white) & $56^{*}$ & 76 & $79^{*}$ & 70 \\
\hline Education (years) & 14.22 & 14.32 & 14.63 & 14.41 \\
\hline Average family size (persons) & 2.86 & 2.61 & 2.77 & 2.77 \\
\hline Income category $(5=\$ 35-50,000 /$ year $)$ & $4.84^{*}$ & 5.10 & 5.68 & 5.24 \\
\hline \multicolumn{5}{|l|}{ Family age structure (no. of persons) } \\
\hline Younger children ( $<9$ years $)$ & $0.52^{*}$ & 0.34 & 0.33 & 0.40 \\
\hline Older children (9-18 years) & 0.54 & 0.43 & 0.46 & 0.48 \\
\hline Young adults (19-35 years) & 0.72 & 0.58 & 0.60 & 0.64 \\
\hline Working adults (36-65 years) & 0.98 & 1.04 & $1.21^{*}$ & 1.09 \\
\hline Retired adults (>65 years) & $0.09^{*}$ & 0.21 & 0.17 & 0.15 \\
\hline Heard of satsumas (\% yes) & 33 & $47^{*}$ & 40 & 39 \\
\hline Tasted satsumas (\% yes) & 29 & 37 & 28 & 31 \\
\hline
\end{tabular}

${ }^{*}$ Significantly different $(p<0.10)$ from overall sample in a two-tail $t$ test.

the marketing implications of the larger coefficients even when their $p$ values are as high as 0.20 or even 0.30 . Moreover, considering that it is a property of marginal probabilities to sum to 0 across the three segments, for every large positive coefficient there is usually a large negative coefficient in one of the other segments, but one coefficient may be conventionally significant while the other is not. For example, if a respondent was surveyed at the store in Huntsville, then that condition increases the probability that the respondent is a member of Segment I by $18.4 \%$ (relative to the reference store, which was Mobile), whereas it would decrease the probability of the respondent being in Segment III by $14.8 \%$, relative to Mobile. However, in the former case the significance level was 0.11 , while in the latter it was only 0.21

The illustration of the store location is simply used to demonstrate the inverse correlation between pairs of larger coefficients, but store/city is otherwise not an actionable demographic because we are not proposing to market satsumas just in that store. However, by having the model assign explanatory power to each store, the interpretation of the remaining actionable demographic variables is independent of store idiosyncrasies.

Some of the interesting marginal probabilities for Segment I are interpreted as follows. If the average age of the overall sample were to increase by 1 year (from 42.8 to 43.8 ), the probability of membership in Segment I would decrease by $0.42 \%$. If a respondent is male, the probability of membership in the no-blemish segment would decrease by $6.5 \%$. If a respondent is white, the probability of that person belonging to the no-blemish segment would decrease by $12.9 \%$. If the average amount of education in the overall sample were to increase by 1 year (from 14.4 to 15.4 years) then the probability of membership would increase by $1.6 \%$. If the number of children under the age of nine, in the average household, increased by one, then the probability of membership would increase by $3.9 \%$. Finally, respondents who had heard of satsumas before the survey, were $13 \%$ less likely to be Segment I, but if they had tasted a satsuma, this increased the probability of membership by $11 \%$.

The customer profile that was developed in the segment average demographics in Table 2, and which is further reinforced here, is that the people who most strongly prefer no blemishes are more likely to be younger, female, black, with young children, and frequent purchasers of sweet citrus who do not mind paying a higher price for larger fruit that is not green and has few seeds. The multinomial logit model based solely on the demographic variables (and not on external attribute level preferences) correctly predicted 125 of the 223 members of Segment I, or $56 \%$. 87 of the remaining members were incorrectly assigned to Segment III by the model (39\%), and another 11 to Segment I (5\%).

Segment II, the price-sensitive consumers, represented $23 \%$ of the sample. Their relative importance for price was $31 \%$, which was almost twice as high as their next most important 
attribute, seeds (Table 2). The lowest price of $\$ 1.07 / \mathrm{kg}$ resulted in a rating increase of 0.97 , or $25 \%$ above the base rating. The highest price of $\$ 4.39$ resulted in a rating decrease of 1.26 , or $32 \%$ below the base rating. Segment II bought significantly fewer citrus from grocery stores than the overall sample (and more from roadside stands and farmers markets), they were significantly older ( 45.9 vs. 42.8 years in the overall sample), and they were more likely to have heard of satsumas before (47\% vs. $39 \%$ overall). $74 \%$ of the members of this segment preferred the lowest price, $26 \%$ actually preferred the middle price, but none preferred the highest price (Table 3). Also, $60 \%$ preferred no seeds, and $65 \%$ preferred the Alabama designation on the production region label.

Table 3. Percentage of respondents who specified the level as their first choice, by segment.

\begin{tabular}{|c|c|c|c|c|}
\hline $\begin{array}{l}\text { Attributes } \\
\text { and levels }\end{array}$ & $\underset{\text { I }}{\text { Segment }}$ & $\underset{\text { II }}{\text { Segment }}$ & $\begin{array}{l}\text { Segment } \\
\text { III }\end{array}$ & $\begin{array}{l}\text { Overall } \\
\text { sample }\end{array}$ \\
\hline \multicolumn{5}{|l|}{ Price/kg } \\
\hline$\$ 1.07$ & 36 & 74 & 33 & 43 \\
\hline$\$ 2.18$ & 40 & 26 & 45 & 39 \\
\hline$\$ 4.39$ & 24 & 0 & 22 & 18 \\
\hline \multicolumn{5}{|l|}{ Size $(\mathrm{cm})$} \\
\hline 5.08 & 13 & 21 & 16 & 16 \\
\hline 6.35 & 35 & 32 & 33 & 33 \\
\hline 7.62 & 52 & 48 & 51 & 51 \\
\hline \multicolumn{5}{|l|}{ Color } \\
\hline Green-yellow & 14 & 24 & 23 & 20 \\
\hline Yellow-orange & 52 & 40 & 44 & 46 \\
\hline Orange & 34 & 36 & 34 & 34 \\
\hline \multicolumn{5}{|l|}{ Number of seeds } \\
\hline 0 & 48 & 60 & 92 & 69 \\
\hline 3 & 29 & 23 & 8 & 19 \\
\hline 7 & 23 & 17 & 0 & 12 \\
\hline \multicolumn{5}{|c|}{ Diameter of surface blemish (mm) } \\
\hline 0 & 84 & 41 & 55 & 63 \\
\hline 19.1 & 10 & 33 & 27 & 22 \\
\hline 28.6 & 6 & 26 & 18 & 16 \\
\hline \multicolumn{5}{|c|}{ Production region label } \\
\hline Alabama & 41 & 65 & 62 & 55 \\
\hline U.S. & 59 & 35 & 38 & 45 \\
\hline \multicolumn{5}{|l|}{ Type of production } \\
\hline Organic & 55 & 54 & 55 & 55 \\
\hline Conventional & 45 & 46 & 45 & 45 \\
\hline
\end{tabular}

Table 4. Marginal probabilities by consumer segment with respect to the vector of demographic variables (computed at the means). ${ }^{\mathrm{z}}$

\begin{tabular}{|c|c|c|c|c|c|c|}
\hline \multirow[b]{3}{*}{ Variable } & \multicolumn{6}{|c|}{ Marginal probabilities of membership in each segment } \\
\hline & \multicolumn{2}{|c|}{ Prob[Segment=I] } & \multicolumn{2}{|c|}{ Prob[Segment=II] } & \multicolumn{2}{|c|}{ Prob[Segment=III] } \\
\hline & Coefficient & $p$ value & Coefficient & $p$ value & Coefficient & $p$ value \\
\hline Intercept & 0.2251 & 0.33 & -0.1017 & 0.63 & -0.1234 & 0.61 \\
\hline \multicolumn{7}{|l|}{ Survey city } \\
\hline Auburn, Ala. & -0.0473 & 0.68 & 0.0855 & 0.34 & -0.0382 & 0.74 \\
\hline Columbus, Ga. & 0.1219 & 0.28 & -0.0254 & 0.78 & -0.0965 & 0.41 \\
\hline Montgomery, Ala. & 0.0609 & 0.59 & -0.0393 & 0.67 & -0.0216 & 0.85 \\
\hline Birmingham, Ala. & 0.0540 & 0.64 & 0.0490 & 0.59 & -0.1030 & 0.37 \\
\hline Gadsden, Ala. & -0.0128 & 0.91 & 0.1224 & 0.18 & -0.1096 & 0.35 \\
\hline e, Ala. & 0.1844 & 0.11 & -0.0361 & 0.71 & -0.1483 & 0.21 \\
\hline Alban & 0.0590 & 0.61 & 0.0219 & 0.81 & -0.0809 & 0.48 \\
\hline Macon & 0.1746 & 0.17 & -0.0214 & 0.85 & -0.1532 & 0.27 \\
\hline Ever eaten sweet citrus $(1=$ yes $)$ & -0.0689 & 0.62 & 0.0923 & 0.54 & -0.0234 & 0.88 \\
\hline Allergic to & 0.0476 & 0.48 & 0.0526 & 0.31 & -0.1002 & 0.21 \\
\hline$\left.\left(h^{-1}\right)\right)$ & 0.0005 & 0.49 & -0.0007 & 0.34 & 0.0002 & 0.79 \\
\hline Where 1 & -0.0105 & 0.87 & -0.0906 & 0.07 & 0.1011 & 0.14 \\
\hline Purchase for special occasion $(1=$ yes $)$ & -0.0391 & 0.37 & -0.0373 & 0.32 & 0.0764 & 0.08 \\
\hline Age (years) & -0.0042 & 0.05 & 0.0035 & 0.05 & 0.0007 & 0.74 \\
\hline Gender $(1=$ male $)$ & -0.0647 & 0.16 & 0.0270 & 0.47 & 0.0377 & 0.40 \\
\hline Ethnicity $(1=$ white $)$ & -0.1290 & 0.02 & 0.0124 & 0.80 & 0.1166 & 0.05 \\
\hline Education & 0.0162 & 0.13 & -0.0 & 0.18 & -0.0042 & 0.69 \\
\hline Income category & -0.0141 & 0.28 & 0.0000 & 1.00 & 0.0140 & 0.29 \\
\hline \multicolumn{7}{|c|}{ Age structure of family (no. of persons) } \\
\hline Younger children $(<9$ years $)$ & 0.0390 & 0.19 & -0.0099 & 0.71 & -0.0291 & 0.36 \\
\hline Older children ( $9-18$ years) & 0.0018 & 0.94 & 0.0070 & 0.75 & -0.0087 & 0.74 \\
\hline Young adults ( $19-35$ years) & -0.0317 & 0.34 & 0.0051 & 0.85 & 0.0368 & 0.27 \\
\hline Working adults ( $36-65$ years) & -0.0257 & 0.43 & -0.0242 & 0.38 & 0.0499 & 0.13 \\
\hline & -0.0338 & 0.59 & -0.0174 & 0.71 & 0.0512 & 0.38 \\
\hline Heard of & -0.1302 & 0.11 & 0.0757 & 0.21 & 0.0545 & 0.45 \\
\hline Tasted satsumas $(1=$ yes $)$ & 0.1108 & 0.21 & 0.0030 & 0.96 & -0.1138 & 0.16 \\
\hline Percentage correctly predicted & \multicolumn{2}{|c|}{$56 \%$} & \multicolumn{2}{|c|}{$16 \%$} & \multicolumn{2}{|c|}{$68 \%$} \\
\hline
\end{tabular}

${ }^{2}$ Multinomial logit model likelihood ratio statistic significant at $p<0.00017$.

Several variables were identified as influencing the marginal probability of being in Segment II, including: sweet citrus purchase location, age, education, and awareness of satsumas (Table 4). For respondents who are known to buy most of their sweet citrus at some place other than a grocery store (e.g., a roadside stand or farmers market), there is a $9.1 \%$ greater likelihood of being in the price-sensitive segment. Age had a small influence-a 1-year increase in average respondent age in the overall sample would lead to only a $0.35 \%$ increase in the probability of segment membership. Similarly, an increase in the average number of years of education in the overall sample only decreased the probability of membership in Segment II by $1.2 \%$. However, for respondents who had heard of satsumas, the probability of being in Segment II increased by $7.6 \%$.

The customer profile that emerges for Segment II is one of relatively older consumers who are more likely to have heard of satsumas and who will buy them if the price is low (particularly at roadside stands and farmers markets), and if there are few seeds and the production region label says Alabama. However, this segment was the most difficult for which to predict membership from demographics alone, and only 22 out of $137(16 \%)$ of the respondents with like preferences were correctly placed by the multinomial logit model in Segment II. Most of the members (76 out of 137, or 55\%) were assigned incorrectly to Segment III, with the other $28 \%$ misplaced in Segment I.

Segment III represented the no-seed segment, and included $41 \%$ of the sample. With a relative importance of $35.4 \%$, the seediness attribute was two to three times more important in their buying decision than color, size, price, or blemishes, which were all around $12 \%$ to $14 \%$ in relative importance. Zero seed produced a $32 \%$ increase in rating over the base rating, while 7 seeds produced a $31 \%$ decrease in rating (Table 2 ). The only demographic variable that was significantly different from the overall sample was ethnicity, with Segment III having more whites. Segment III's strong preference for no seed showed the highest percentage of first choices for any level of any segment, 92\% (Table 3). Only 8\% preferred 3 seeds, and no one preferred 7 seeds. $67 \%$ actually preferred one of the higher prices, $62 \%$ preferred the Alabama production region label, $55 \%$ preferred no blemishes, and $51 \%$ preferred the largest size.

There were 6 variables with significant marginal probabilities, including: allergic to sweet citrus (no), purchase location (grocery stores), special occasion purchasing (yes), ethnicity (white), working adults (36 to 65), and tasted satsumas (no) (Table 4). A respondent who is not allergic to sweet citrus has a $10 \%$ higher probability of being in Segment III. Respondents that purchase most of their sweet citrus at a grocery store have a $10 \%$ increase in probability of being in Segment III, while those that purchase sweet citrus on special occasions increase their probability of membership by $7.6 \%$. Other characteristics that increased the likelihood of being in the no-seed 
segment were ethnicity (white), households with working adults, and never having tasted a satsuma. All this suggests a profile of a customer who is white, buys citrus in grocery stores particularly for special occasions, is relatively unfamiliar with satsumas, but who will pay a higher price to get fruit that are seedless, larger, not green or blemished, and preferably from Alabama. The multinomial logit model, using only the demographics as independent variables, correctly predicted 166 of the 245 members with like preferences, for a $68 \%$ accuracy score, the highest of any of the segments. Another 64 respondents were inaccurately placed in Segment I (26\%), and 15 in Segment II (6\%).

\section{Conclusion}

The information collected from this survey is important in understanding consumer preferences for external attributes and identifying consumer markets for satsumas. In terms of preferences, respondents expressed an overall liking for low-priced, high-quality fruit that is larger, blemish-free, non-green, and seedless. Production region label and type of production were of little consequence. However, segmentation results showed that the various attributes were valued at considerably different levels by different consumers. For example, some consumers valued the lowest prices extremely, while others barely distinguished between the lowest and middle priced fruit. Nonnegligible proportions of consumers (12\% to $20 \%$ ) actually preferred higher prices, smaller sizes, greenish skin color, seeds, and blemishes (though not all in the same fruit).

Deriving marginal probabilities of segment membership from demographic information allows segments to be differentiated from each other not just by their preferences for external attributes, but more importantly by criteria that are actionable by marketing techniques. Consumers who strongly dislike blemishes cannot be identified by their appearance as they walk in the store, so it is helpful to characterize them as being more likely to be of a younger age, with young children, non-white, and female. These descriptions are not completely accurate, but they can allow marketing managers to target these segments through their demographic characteristics, which are observable and measurable. All this information then flows back up the marketing channel, ultimately to the producer, who is now in a better position to understand, and make informed decisions about, the trade-offs between higher-valued fruit and higher costs of production.

\section{Literature Cited}

Baidu-Forson, J., B.R. Ntare, and F. Waliyar. 1997. Utilizing conjoint analysis to design modern crop varieties: empirical example for groundnut in Niger. Agr. Econ. 16(3):219-226.

Baker, G.A. 1998. Strategic implications of consumer food safety preferences - Consumerconcerns and willingness-to-pay. Intl. Food Agribus. Mgt. Rev. 1(4):451-463.

Baker, G.A. 1999. Consumer preferences for food safety attributes in fresh apples: Market segments, consumer characteristics, and marketing opportunities. J. Agr. Resour. Econ. 24(1):80-97.

Baker, G.A. and T.A. Burnham. 2002. The market for genetically modified foods: Consumer characteristics and policy implications. Intl. Food Agribus. Mgt. Rev. 4(4):351-360.

Baker, G.A. and P.J. Crosbie. 1994. Consumer preferences for food safety attributes: A market segment approach. Agribusiness: An Intl. J. 10(4):319-324.

Behe, B., R. Nelson, S. Barton, C. Hall, C.D. Safley, and S. Turner. 1999. Consumer preferences for geranium flower color, leaf variegation, and price. HortScience 34:740-742.

Dozier, H.L. 1924. Insects, pests, and diseases of the satsuma orange. Gulf Coast Citrus Exchange Educ. Bul. 1.

Ebel, R.C., W.A. Dozier, B. Hockema, F.M. Woods, R. Thomas, B.S. Wilkins, M. Nesbitt, and R. McDaniel. 2003. Fruit quality of satsuma mandarin grown on the northern coast of the Gulf of Mexico. HortScience 39:979-982.

Fotopoulos, C. and A. Krystallis. 2001. Are quality labels a real marketing advantage? A conjoint application on Greek PDO protected olive oil. J. Intl. Food Agribus. Mktg. 12(1):1-22.

Frank, C.A., R.G. Nelson, E.H. Simonne, B.K. Behe, and A.H. Simonne. 2001. Consumer preferences for color, price, and vitamin $\mathrm{C}$ content of bell peppers. HortScience 36:795-800.

Gillespie, J., G. Taylor, A. Schupp, and F. Wirth. 1998. Opinions of professional buyers toward a new, alternative red meat: Ostrich. Agribusiness: An Intl. J. 14(3):247-256.

Gineo, W.M. 1990. A conjoint/logit analysis of nursery stock purchases. N.E. J. Agr. Res. Econ. 19(1):49-58.

Green P.E. and K. Helsen. 1989. Cross-validation assessment of alternatives to individual-level conjoint analysis: A case study. J. Mktg. Res. 26:346-350.

Green, P.E., A.M. Krieger, and Y. Wind. 2001. Thirty years of conjoint analysis: Reflections and prospects. Interfaces 31(3):S56-S73.

Greene, W.H. 1995. LIMDEP, version 7.0: User's manual. Econometric Software, Plainview, N.Y.

Hair, Jr., J.F., R.E. Anderson, R.L. Tatham, and W.C. Black. 1998. Multivariate data analysis. $5^{\text {th }}$ ed. Prentice Hall, Upper Saddle River, N.J.

Halbrendt, C.K., F.F. Wirth, and G.F. Vaughn. 1991. Conjoint analysis of the mid-Atlantic food-fish market for farm-raised hybrid striped bass. S. J. Agr. Econ. 23(1):155-163.

Harrison, R.W., A. Ozayan, and S.P. Meyers. 1998. A conjoint analysis of new food products processed from underutilized small crawfish. J. Agr. Appl. Econ. 30(2):257-265.
Holland, D. and C.R. Wessells. 1998. Predicting consumer preferences for fresh salmon: The influence of safety inspection and production method attributes. Agr. Res. Econ. Rev. 27:1-14.

Huang, C.L. and J. Fu. 1995. Conjoint analysis of consumer preferences and evaluations of a processed meat. J. Intl. Food Agribus. Mktg. 7(1):35-53.

Kelley, K.M., B.K. Behe, J.A. Biernbaum, and K.L. Poff. 2001. Consumer preference for edible-flower color, container size, and price. HortScience 36:801-804.

Kelley, K.M., B.K. Behe, J.A. Biernbaum, and K.L. Poff. 2002. Combinations of colors and species of containerized edible flowers: effect on consumer preferences. HortScience 37:218-221.

Lin, B., S. Payson, and J. Wertz. 1996. Opinions of professional buyers toward organic produce: Acase study of mid-Atlantic market for fresh tomatoes. Agribusiness: An Intl. J. 12(1):89-97.

Manalo, A.B. 1990. Assessing the importance of apple attributes: an agricultural application of conjoint analysis. N.E. J. Agr. Res. Econ. 19(2):118-124.

Martínez, M.G., Z. Aragonés, and N. Poole. 2002. A repositioning strategy for olive oil in the UK market. Agribusiness: An Intl. J. 18:163-180.

McGuire, R.G. 1992. Reporting of objective color measurement. HortScience 27:1254-1255.

Nelson, R.G., C.M. Jolly, M.J. Hinds, Y. Donis, and E. Prophete. 2004. Consumer preferences for peanut butter (mamba) products in Haiti: Aconjoint analysis. Peanut Sci. (in press).

Powell, A. and D. Williams. 1998. Citrus for southern and coastal Alabama. Ala. Coop. Ext. Syst. Bul. ANR-60398.

Robertson, J.L. and L.H. Chatfield. 1982. Fresh flower merchandising in loose bunches. HortScience 17:593-595.

Rucker, B.R. 1996. Satsumaland! A history of citrus culture in west Florida. Gulf Coast Historical Review. (Fall):62-75.

SAS Institute Inc. 1987. SAS user's guide: Statistics, $5^{\text {th }}$ ed. SAS Institute Inc., Cary, N.C.

Shafer, B.S. and J.W. Kelly. 1986. The influence of cultivar, price, and longevity on consumer preferences for potted chrysanthemums. HortScience 21:1412-1413

Townsley-Brascamp, W. and N.E. Marr. 1995. Evaluation and analysis of consumer preferences for outdoor ornamental plants. Acta Hort. 391:199-206.

U. S. Department of Agriculture - Agricultural Marketing Service, Fruit and Vegetable Programs, Fresh Products Branch. 2002. 10 July 2002. $<$ http://www.ams.usda.gov/standards/tangerin. pdf $>$.

van der Pol, M. and M. Ryan. 1996. Using conjoint analysis to establish consumer preferences for fruit and vegetables. Brit. Food J. 98(8):5-12.

Voss, D. H. 1992. Relating colorimeter measurement of plant color to the Royal Horticultural Society colour chart. HortScience 27:1256-1260.

Walheim, L. 1996. Citrus: Complete guide to selecting and growing more than 100 varieties for California, Arizona, Texas, the Gulf Coast, and Florida. Millard Publ. Serv. and Eric A. Johnson Co., Korea.

Winberg, O.F.E. 1948. The satsuma. Fairhope Courier. November. 